\title{
Effect of 5-Fluorouracil Pretreatment on the In Vitro Drug Release from Colon-Targeted Guar Gum Matrix Tablets
}

\author{
Y.S.R. Krishnaiah ${ }^{*, 1}$ and B.P. Srinivas ${ }^{2}$ \\ ${ }^{I}$ Department of Pharmaceutics, Faculty of Pharmacy, Kuwait University, PO Box 24923, Safat 13110, Kuwait City, \\ Kuwait \\ ${ }^{2}$ University College of Pharmaceutical Sciences, Andhra University, Visakhapatnam, India
}

\begin{abstract}
The aim of the investigation was to assess the effect of oral 5-flourouracil pre-treatment on the in vitro drug release from a model colon-targeted guar gum matrix tablet formulation of mebendazole. Guar gum matrix tablets of mebendazole were subjected to in vitro drug release studies in simulated colonic fluids $(4 \% \mathrm{w} / \mathrm{v}$ of rat caecal contents) obtained after oral treatment of rats either with varying doses of 5-fluorouracil $\left(0.3,1,3\right.$ or $6 \mathrm{mg} \mathrm{kg}^{-1}$ once daily for 5 days) and $1 \mathrm{ml}$ of $2 \% \mathrm{w} / \mathrm{v}$ of guar gum dispersion or with $1 \mathrm{ml}$ of $2 \% \mathrm{w} / \mathrm{v}$ of guar gum dispersion alone (control study) after completing the dissolution study in $0.1 \mathrm{M} \mathrm{HCl}(2 \mathrm{~h})$ and $\mathrm{pH} 7.4$ Sorensen's phosphate buffer $(3 \mathrm{~h})$. The mebendazole tablets disintegrated in the presence of simulated colonic fluids releasing about $97 \%$ of the drug (control study) at the end of $24 \mathrm{~h}$. However, the release of mebendazole decreased when drug release studies were carried out in caecal contents of rats pretreated with both 5-fluorouracil and guar gum dispersion. The release of mebendazole significantly decreased when pretreated with 1, 3 or $6 \mathrm{mg} \mathrm{kg}^{-1}$ dose levels of 5-fluorouracil (oral). However, there was no significant effect of 5fluorouracil on the release of mebendazole when pretreated at a dose level of $0.3 \mathrm{mg} \mathrm{kg}^{-1}$ (oral). It was concluded that multiple administration of 5-fluorouracil at a dose of $0.3 \mathrm{mg} \mathrm{kg}^{-1}$ did not affect the drug release from colon-targeted guar gum matrix tablets.
\end{abstract}

Keywords: 5-Fluorouracil, guar gum, mebendazole, colon targeting, matrix tablets, in vitro drug release.

\section{INTRODUCTION}

The most promising colon-specific drug delivery systems are those based on the enzymatic action of colonic bacteria on polysaccharides. The microflora of colon is in the range of $10^{11}-10^{12} \mathrm{CFU} \mathrm{ml}{ }^{-1}$ [1] consisting mainly of anaerobic bacteria, e.g. Bacteroides, Bifidobacteria, Eubacteria, Clostridia, Enterococci, Enterobacteria and Ruminococcus etc. This vast microflora fulfills its energy needs by fermenting various types of substrates that have been left undigested in the small intestine, e.g. di- and tri-saccharides, polysaccharides etc. [2,3]. For the fermentation of these polysaccharides, the microflora of GIT produces a vast number of enzymes like $\beta$-glucoronidase, $\beta$-xylosidase, $\alpha$-arabinosidase, $\beta$-galactosidase, nitroreductase, azareducatase, deaminase and urea dehydroxylase [4]. Because of the presence of these enzymes only in the colon, the use of biodegradable polymers for colon-targeted drug delivery seems to be a more site-specific approach when compared to other approaches. These polymers shield the drug from the environments of stomach and small intestine, and are able to deliver the drug to the colon. On reaching the colon, they undergo assimilation by micro-organism [5] or degradation by enzymes [6,7] or break down of the polymer back bone [8,9] leading to a subsequent reduction in their molecular weight and thereby

*Address correspondence to this author at the Department of Pharmaceutics, Faculty of Pharmacy, Kuwait University, PO Box 24923, Safat 13110, Kuwait City, Kuwait; Tel: 00965-498-6034; Fax: 00965-498-6843;

E-mail: ysrkrishnaiah@hsc.edu.kw or ysrkrishnaiah@yahoo.co.in loss of mechanical strength. They are then unable to hold the drug entity any longer and release the drug in colon [10]. The various polysaccharides investigated as a carrier for colon-specific drug delivery are pectin, chondroitin sulphate, amylose etc. [11-13]. In this context, studies were carried out to evaluate the usefulness of guar gum as a carrier for colonspecific drug delivery [14-16]. Guar gum is a natural nonionic polysaccharide derived from seeds of Cyamopsis tetragonolobus (Family: Leguminaciae). It consists of linear chains of $(1 \rightarrow 4)-\beta$-D mannopyranosyl units with $\alpha$-Dgalactopyranosyl units attached by $(1 \rightarrow 6)$ linkages [17]. Guar gum-based colonic drug delivery systems were developed for mebendazole [18], metronidazole [19], celecoxib [20] etc.

The drug of choice in the treatment of carcinoma of stomach, colon, rectum, breast, ovary, and urinary bladder is 5-fluorouracil [21]. For several decades, 5-fluorouracil stood alone as the only chemotherapeutic agent with clinical activity against colorectal cancer. Numerous active 5-fluorouracil schedules are in clinical use, but erratic oral bioavailability has historically mandated intravenous administration [22]. On intravenous administration, 5-fluorouracil produces severe systemic toxic effects including gastrointestinal, hematological, neural, cardiac and dermatological origin [23]. Most of these systemic side effects are due to the cytotoxic effect of 5-fluorouracil after reaching the unwanted sites. Targeted delivery of 5-fluorouracil to colon not only reduces systemic side effects, but also provides an effective and safe therapy of colorectal cancer with reduced dose and reduced duration of therapy. To achieve colon-targeted delivery of 5- 
fluorouracil, guar gum was applied as a compression coat over 5-fluorouracil core tablets that prevented the drug release in the physiological environment of stomach and small intestine yet released the drug in the physiological environment of colon [24].

In view of the cytotoxic effect of 5-fluorouracil [23], the drug released from the first dose of guar gum-based colon targeted tablets of 5-fluorouracil [24] might inactivate the microbial flora of colon which in turn may not be able to disintegrate the concomitantly administered guar gum formulation, and thus hamper 5-fluorouracil release in colon. This assumption was based on the fact that drug release from guar gum formulations occurs due to their disintegration by colonic bacteria [14-16]. Thus, it is essential to investigate whether the guar gum-based formulations of 5-flourouracil would disintegrate and release the drug on multiple administration to humans. Hence, it was planned to study the effect of 5-fluorouracil pretreatment on the in vitro drug release from a model guar gum-based colon-targeted tablets. Guar gum matrix tablets of mebendazole, developed for an effective and safe therapy of helmenthiasis, was chosen as a model formulation [18]. The present study describes the in vitro drug release studies on guar gum matrix tablets of mebendazole in rat caecal contents obtained after treatment with either guar gum dispersion [14] alone (control) or guar gum dispersion and 5-flourouracil. The difference in drug release profile is expected to reveal the possible adverse effect of 5fluorouracil on the colon-targeting ability of the chosen model formulation of guar gum matrix tablets of mebendazole.

\section{MATERIALS AND METHODS}

\section{Materials}

Mebendazole (98-101\% purity) and tinidazole (98.6 to $101.4 \%$ purity) were gratis from M/s CIPLA Ltd., Bangalore India and $\mathrm{M} / \mathrm{s}$ East India Pharmaceutical Works Limited, Kolkata, India respectively. 5-Fluorouracil (98 to $99 \%$ purity) was obtained M/s Lancaster synthesis, England. Guar gum (viscosity of $1 \%$ aqueous dispersion is $125 \mathrm{cps}$; particle size $<75 \mu \mathrm{m}$ ) was a gift sample obtained from M/s Dabur India Limited, India, and was of pharmacopoeia quality (USP/NF). Acetonitrile (HPLC grade) and glacial acetic were obtained from M/s Qualigens Fine Chemicals, Mumbai, India. Water used was of HPLC grade. Other materials used in the study such as microcrystalline cellulose (MCC, Avicel, FMC Type $\mathrm{pH}-105)$, starch, magnesium stearate and talc were of pharmacopoeia quality (USP/NF).

\section{Preparation of Guar Gum Matrix Tablets of Mebenda- zole}

Matrix tablets of mebendazole containing $20 \%$ of guar gum were prepared by wet granulation method as described previously [18]. The composition of the matrix formulations, used in the study, containing $50 \mathrm{mg}$ of mebendazole was shown in Table 1. Guar gum was sieved $(<250 \mu \mathrm{m})$ separately and mixed with mebendazole $(<150 \mu \mathrm{m})$ and MCC $(<$ $250 \mu \mathrm{m})$. The powders were blended and granulated with $10 \%$ starch paste. The wet mass was passed through a mesh $(1680 \mu \mathrm{m})$ and the granules were dried at $50{ }^{\circ} \mathrm{C}$ for $2 \mathrm{~h}$. The dried granules were passed through a mesh $(1190 \mu \mathrm{m})$ and the resulting granules were lubricated with a mixture of talc and magnesium stearate $(2: 1)$. The lubricated granules were compressed at a compression force of $4500-5500 \mathrm{~kg}$ using 9 $\mathrm{mm}$ round, flat and plain punches on a single station tabletting machine (M/s Cadmach Machinery Co. Pvt. Ltd., India). The matrix tablets were tested for their hardness, drug content and drug release characteristics with a suitable number of tablets for each test. The hardness of the matrix tablets was determined by using Monsanto Hardness Tester.

Table 1. Composition of Mebendazole Matrix Tablets Containing $20 \%$ of Guar Gum

\begin{tabular}{|l|c|}
\hline \multicolumn{1}{|c|}{ Ingredients } & Quantity (mg) Present in Each Tablet \\
\hline \hline Mebendazole & 50 \\
\hline Guar gum & 60 \\
\hline MCC & 151 \\
\hline Starch (added as paste) & 30 \\
\hline Talc & 6 \\
\hline Magnesium stearate & 3 \\
\hline Total & 300 \\
\hline
\end{tabular}

\section{HPLC Analysis of Mebendazole}

The quantitative determination of mebendazole was performed by High Performance Liquid Chromatography (HPLC). A Shimadzu HPLC system (Shimadzu, Japan) with two LC-10AT VP pumps, a SPD-10A VP variable wavelength UV/VIS detector, a CTO-10AS VP column oven, an SCL-10A VP system controller (Shimadzu) and a RP C-18 column (150 mm x $4.6 \mathrm{~mm}$ I.D.; particle size $5 \mu \mathrm{m}$; Flexit Inc., Pune, India) was used. The HPLC system was equipped with the software "Class-VP series version 5.03 (Shimadzu)".

The mobile phase used was acetonitrile and water containing $0.35 \%$ of triethylamine ( $\mathrm{pH}$ adjusted to 3.8 with $5 \%$ o-phosphoric acid) in the ratio of 44:56. The filtered mobile phase was pumped at a flow rate of $0.8 \mathrm{ml} \mathrm{min}^{-1}$. The column temperature was maintained at $40{ }^{\circ} \mathrm{C}$. The eluent was detected by UV detector at $254 \mathrm{~nm}$, and the data were acquired, stored and analyzed with the software "Class-VP series version 5.03 (Shimadzu)". A standard curve was constructed for mebendazole in the range of 0.1 to $40 \mu \mathrm{g} \mathrm{ml}^{-1}$ using tinidazole as internal standard. A good linear relationship was observed between the concentration of mebendazole and the ratio of the peak area of mebendazole to that of tinidazole (internal standard) with a high correlation coefficient $(r=0.9999)$. The required studies were carried out to estimate the precision and accuracy of this HPLC method of analysis of mebendazole. The method was found to be highly precise (CV less than 2.2\%) and accurate (mean recovery 96\%). The HPLC method was validated for the possible interference of rat caecal contents by adding known quantity of the drug $\left(5 \mu \mathrm{g} \mathrm{ml}^{-1}\right)$ to rat caecal content medium containing internal standard and conducting recovery studies. None of the peaks interfered either with that of drug or internal standard. Also, there was a good recovery of the drug (about $98.4 \%$ ). This indicates that the rat caecal contents did not 
interfere in the HPLC estimation the drug. The standard curve, constructed as described above, was used for estimating mebendazole either in the matrix tablets or in dissolution fluids.

\section{Quantitative Determination of Drug Content in Tablets}

The mebendazole matrix tablets were tested for their drug content. Ten tablets were finely powdered; $100 \mathrm{mg}$ of the powder was accurately weighed and transferred to 100$\mathrm{ml}$ volumetric flask. Initially about $50 \mathrm{ml}$ of glacial acetic acid was added to the flask and allowed to stand for $6 \mathrm{~h}$ with intermittent sonication to ensure complete solubility of the drug. Then the volume was made up with glacial acetic acid, the mixture centrifuged, $1 \mathrm{ml}$ of the supernatant liquid suitably diluted, filtered and analysed for mebendazole content by reverse phase HPLC method as described above.

\section{Plan of Study}

In vitro drug release study was carried out on guar gum matrix tablets of mebendazole in the presence of $0.1 \mathrm{M} \mathrm{HCl}$ $(2 \mathrm{~h}), \mathrm{pH}$ 7.4 Sorensen's buffer [25] $(3 \mathrm{~h})$ and in simulated colonic fluids-II. The simulated colonic fluid-II is $\mathrm{pH} 6.8$ phosphate buffered saline [25] containing $4 \% \mathrm{w} / \mathrm{v}$ of rat caecal contents obtained after oral treatment with both $1 \mathrm{ml}$ of $2 \% \mathrm{w} / \mathrm{v}$ of guar gum dispersion (once daily for 7 days) and 5 -fluorouracil $\left(0.3,1,3\right.$ or $6 \mathrm{mg} \mathrm{kg}^{-1}$ once daily for 5 days). The drug release study was repeated in the presence of $0.1 \mathrm{M}$ $\mathrm{HCl}(2 \mathrm{~h}), \mathrm{pH}$ 7.4 Sorensen's buffer $(3 \mathrm{~h})$ and in simulated colonic fluids-I. The simulated colonic fluid-I is $\mathrm{pH} 6.8$ phosphate buffered saline containing $4 \%$ w/v of caecal contents of rats orally treated for 7 days only with $1 \mathrm{ml}$ of guar gum dispersion (control). The mean percent of mebendazole released in the presence of rat caecal contents obtained with and without 5-fluorouracil pretreatment was compared to assess whether the 5-fluorouracil pretreatment affected the disintegration of guar gum tablets in physiological environment of colon or not.

\section{Preparation of Simulated Colonic Fluids-I}

Male albino rats (supplied by M/s Ghosh Enterprises, Kolkata, India) weighing 105-115 g and maintained on a normal diet (Bengal gram purchased in local market and soaked in water, $25 \mathrm{~g}$ per rat) were used for the study. The care of the rats was in accordance with the institutional guidelines. It was reported from our laboratory that rat caecal content medium at $4 \% \mathrm{w} / \mathrm{v}$ level obtained after 7 days of enzyme induction with $1 \mathrm{ml}$ of $2 \% \mathrm{w} / \mathrm{v}$ guar gum dispersion provide the best conditions for assessing the susceptibility of guar gum to colonic bacterial degradation [14]. Hence, the rats were treated with guar gum dispersion for inducing the enzymes specifically acting on guar gum. The procedure involved oral treatment of rats with $1 \mathrm{ml}$ of $2 \% \mathrm{w} / \mathrm{v}$ guar dispersion for 7 days. Thirty minutes before the commencement of drug release studies, six rats were euthanized, using carbon dioxide asphyxiation. The abdomen were opened, the caecai traced, ligated at both ends, dissected and immediately transferred into $\mathrm{pH}$ 6.8 PBS, previously bubbled with $\mathrm{CO}_{2}$. The caecal bags were opened, their contents individually weighed, pooled and then suspended in PBS to give $4 \%$ $\mathrm{w} / \mathrm{v}$ dilution. As the caecum is naturally anaerobic, all these operations were carried out under $\mathrm{CO}_{2}$.

\section{Preparation of Simulated Colonic Fluids-II}

On each day, the rats were administered orally with $1 \mathrm{ml}$ of $2 \% \mathrm{w} / \mathrm{v}$ guar gum dispersion, and after $12 \mathrm{~h}$ of the day, they were treated orally with aqueous solution of 5fluorouracil in different doses $\left(0.3,1,3\right.$ or $6 \mathrm{mg} \mathrm{kg}^{-1}$ once daily for 5 days). On $6^{\text {th }}$ day, thirty minutes before the commencement of drug release studies, six rats were euthanized and the caecal contents were obtained as described previously.

\section{In Vitro Drug Release Studies}

The susceptibility of guar gum matrix tablets of mebendazole to the enzymatic action of colonic bacteria was assessed by continuing the drug release studies in $100 \mathrm{ml}$ of simulated colonic fluids-I ( $\mathrm{pH} 6.8$ phosphate buffered saline containing $4 \% \mathrm{w} / \mathrm{v}$ of caecal contents of rats treated only with guar gum dispersion) after completing the first five hours of study in both $0.1 \mathrm{M} \mathrm{HCl}(900 \mathrm{ml} ; 2 \mathrm{~h})$ and $\mathrm{pH} 7.4$ Sorensen's phosphate buffer $(900 \mathrm{ml} ; 3 \mathrm{~h})$. The drug release studies were carried out in a USP dissolution rate test apparatus (Apparatus 1, $100 \mathrm{rpm}, 37^{\circ} \mathrm{C}$ ) with slight modification. A beaker (capacity 150-ml) containing $100 \mathrm{ml}$ of dissolution medium was immersed in the water contained in the 1000-ml vessel, which was, in turn, in the water bath of the apparatus. The tablets were placed in the baskets of the apparatus and immersed in the dissolution medium containing rat caecal contents. The experiment was carried out with continuous $\mathrm{CO}_{2}$ supply into the medium to simulate anaerobic environment of the caecum. The dissolution samples were obtained at $2,5,8,12,18$ and $24 \mathrm{~h}$.

The in vitro drug release studies were repeated in the same way as described above in the presence of simulated colonic fluids-II ( $\mathrm{pH} 6.8$ phosphate buffered saline containing $4 \% \mathrm{w} / \mathrm{v}$ of caecal contents of rats treated with both guar gum dispersion and 5-fuorouracil). The drug release was measured at 2, 5, 8, 12, 18 and $24 \mathrm{~h}$. The amount of drug in the entire quantity of the dissolution medium, i.e., either 900 $\mathrm{ml}$ of $0.1 \mathrm{M} \mathrm{HCl}, 900 \mathrm{ml}$ of $\mathrm{pH} 7.4$ phosphate buffer or 100 $\mathrm{ml}$ of rat caecal content medium (simulated colonic fluids-I or simulated colonic fluids-II) at the end of $24 \mathrm{~h}$ of study was estimated by HPLC to account for the total amount of drug released. The dissolution samples were transferred to $10-\mathrm{ml}$ volumetric flask containing $1 \mathrm{ml}$ of glacial acetic acid and 20 $\mu \mathrm{g}$ of tinidazole solution (internal standard), sonicated well for complete dissolution of the drug, made upto volume with the respective drug-free dissolution medium, centrifuged, filtered through a $0.4-\mu \mathrm{m}$ membrane filter and the filtrate subjected to HPLC analysis as described above.

The drug content remained in either the mass of the formulation or swollen formulation was also determined by HPLC to account for the total amount of drug present in the formulation. This ensured the estimation of all the finely suspended drug particles that may be released from the guar gum matrix formulation on erosion by colonic bacteria. The swollen tablets or residual mass was transferred into a volumetric flask (100-ml) by washing with water, added with 50 $\mathrm{ml}$ of glacial acetic acid and allowed to stand for $6 \mathrm{~h}$ with intermittent sonication to ensure complete solubility of the drug. Then the volume was made up to $100 \mathrm{ml}$ with glacial acetic and the mixture was centrifuged. A 1-ml volume of 
the supernatant liquid was added up with internal standard, suitably diluted with drug-free $\mathrm{pH} 6.8 \mathrm{PBS}$, filtered and analyzed for mebendazole content by HPLC.

\section{Statistical Analysis}

The observed difference in the percent of mebendazole released in dissolution study with simulated colonic fluids-I and simulated colonic fluids-II was tested by using analysis of variance (ANOVA) and Duncan's multiple range test with the help of the STATISTICA program (Release 4.5, StatSoft Inc., 1993). A value of $P<0.05$ was considered statistically significant.

\section{RESULTS AND DISCUSSION}

The rat caecal content medium obtained after pretreatment of rats with guar gum dispersion for 7 days was proved to disintegrate and release the drug from guar gum matrix tablets [14]. The subsequent reports involving the use of gamma scintigraphy studies in human volunteers provided further evidence in this direction $[15,16]$. Based on these reports, several formulations were developed [18-20] including 5-fluorouracil [24]. Thus, the use of rat caecal content medium is highly justified for assessing the possible adverse effect of 5-fluorouracil pre-treatment on the usefulness of guar gum formulations. It was reported earlier that matrix tablets of mebendazole containing $20 \%$ of guar gum were potential in targeting mebendazole to colon [18], and hence were chosen as model formulation. The matrix tablets were prepared by applying maximum force of compression and the hardness of the tablets was in the range of 5.0 to $5.5 \mathrm{~kg}$ $\mathrm{cm}^{-2}$. When subjected to content uniformity test, the matrix tablets were found to contain about $98 \%$ of mebendazole indicating the uniformity of the drug content. Guar gum tablets of mebendazole were subjected to in vitro dissolution study in the presence of either simulated colonic fluids-I $\mathrm{pH}$ 6.8 phosphate buffered saline containing $4 \% \mathrm{w} / \mathrm{v}$ of caecal contents of rats treated with guar gum dispersion alone) or simulated colonic fluids-II ( $\mathrm{pH} 6.8$ phosphate buffered saline containing $4 \% \mathrm{w} / \mathrm{v}$ of caecal contents of rats treated with both guar gum dispersion and different doses of 5-fluorouracil) after completing the first $5 \mathrm{~h}$ of study in $0.1 \mathrm{M} \mathrm{HCl}(900 \mathrm{ml}$; $2 \mathrm{~h})$ and $\mathrm{pH}$ 7.4 Sorensen's phosphate buffer $(900 \mathrm{ml} ; 3 \mathrm{~h})$. When the drug content remained either in the tablet mass or in the swollen matrix formulation was determined and added to the total drug released in the dissolution study, it was found equal to the total amount of drug (mebendazole) present in the formulation indicating a mass balance.

In the presence of simulated colonic fluids-I, the formulation degraded into 2 to 3 pieces at the end of $24 \mathrm{~h}$ of study thereby released a total of about $97 \%$ of mebendazole. But in dissolution medium without rat caecal contents, only $57 \%$ of the drug was released (Fig. 1). This difference in the amount of drug released at the end of $8,12,18$ and $24 \mathrm{~h}$ was highly significant $(\mathrm{P}<0.001)$ when compared to the amount released without rat caecal contents. This indicated that drug release was not due to mechanical erosion, but due to the disintegration of the swollen guar gum matrix tablets by colonic bacterial enzymes [18]. This is based on the reports [26-28] that the anaerobic bacteria (B. fragilis, B. ovatus, $B$. variabilis, B. uniformis, B. distasonis and B. thetaiotaomi- cron) present in the colon are responsible for the degradation of guar gum.

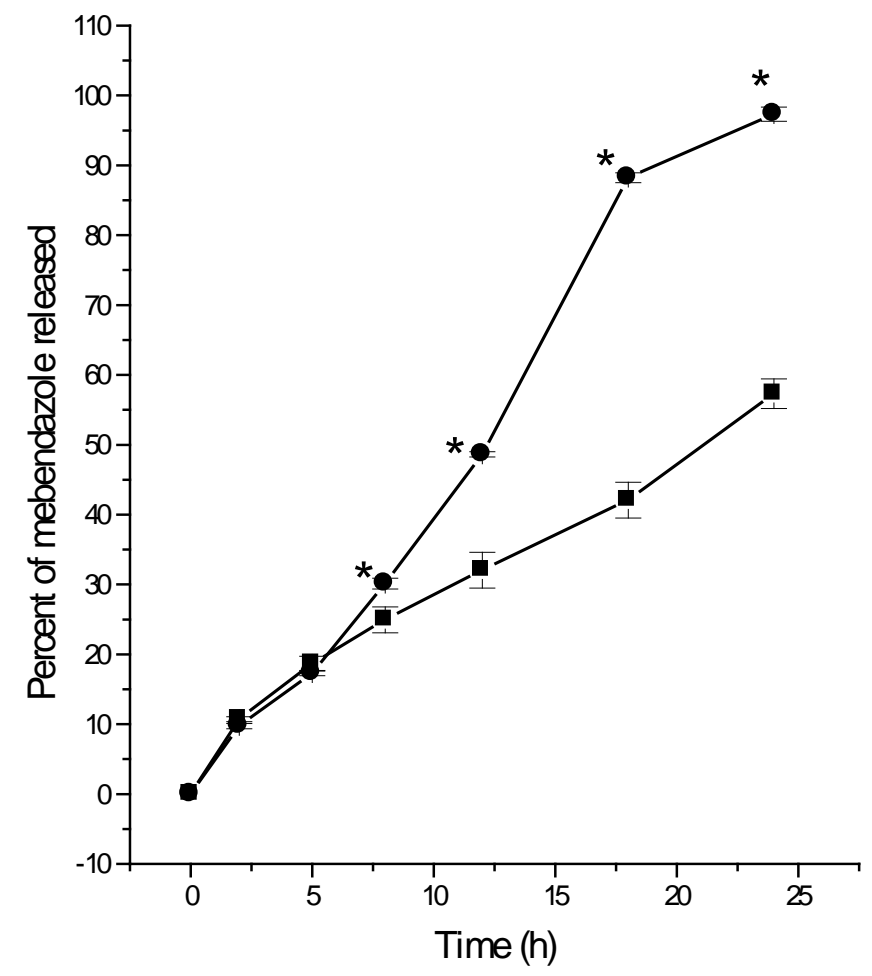

Fig. (1). Mean $( \pm$ S.D.) percent of mebendazole released from the guar gum matrix tablets $(\mathrm{n}=3)$ without $[\bullet]$ and with $(\bullet)$ rat caecal contents medium. *: Significant at $\mathrm{P}<0.001$.

The results of the in vitro drug release studies in simulated colonic fluids-I showed that majority of mebendazole was released (97\%) from the guar gum matrix tablets. Hence, the matrix tablets of mebendazole containing $20 \%$ of guar gum were chosen as a model formulation to assess the effect of 5-fluorouracil pretreatment on the usefulness of guar gum as a colon-specific drug carrier in targeting guar gum matrix tablets of 5-fluorouracil on multiple administration.

The present study was carried out to find out the dose level of 5-fluorouracil pre-treatment that might affect the drug release from the guar gum matrix tablets of mebendazole (model formulation). Thus, the initial study was started randomly at a dose level of $6 \mathrm{mg} \mathrm{kg}^{-1}$ body weight, and progressively decreased to $0.3 \mathrm{mg} \mathrm{kg}^{-1}$ body weight. When drug release studies were conducted in simulated colonic fluids-II, the degradation of guar gum matrix formulation by colonic bacterial was found to vary with the dose of 5-fluorouracil. The maximum oral dose of 5-fluorouracil administered to the rats was $6 \mathrm{mg} \mathrm{kg}^{-1}$ body weight [21]. In caecal contents of rats treated with $6 \mathrm{mg} \mathrm{kg}^{-1}$ of 5-fluorouracil, the swollen guar gum matrix formulation was intact releasing only $49 \%$ of mebendazole (Fig. 2). The oral treatment of 5-fluorouracil at a dose of $6 \mathrm{mg} \mathrm{kg}^{-1}$ significantly $(\mathrm{P}<0.001)$ decreased the percent of mebendazole released from matrix formulation when compared to the drug released using simulated colonic fluids-I (control study). In caecal contents of rats treated with lower dose of 5-fluorouracil $\left(3 \mathrm{mg} \mathrm{kg}^{-1}\right)$, the guar gum matrix formulation was intact and released $51 \%$ of mebendazole (Fig. 2). The decrease in mebendazole release was statistically significant $(\mathrm{P}<0.001)$ after treatment with $3 \mathrm{mg} \mathrm{kg}^{-1}$ of 5-fluorouracil when compared to control study. However, 
with a further decrease in the dose of 5-fluorouracil $(1 \mathrm{mg}$ $\mathrm{kg}^{-1}$ or $0.3 \mathrm{mg} \mathrm{kg}^{-1}$, oral), the formulation disintegrated into 2 to 3 pieces thereby released majority of its drug content (Fig. 3). After treatment with $1 \mathrm{mg} \mathrm{kg}^{-1}$ of 5-fluorouracil, the percent of drug released at the end of $24 \mathrm{~h}$ was $95.8 \pm 0.5$ whereas in control study it was $97.3 \pm 1.0$ wherein the difference was significant $(P<0.05)$. However, the percent of drug released at 12 and $18 \mathrm{~h}$ was significantly lower $(\mathrm{P}<$ $0.01)$ when compared to control. This indicated that 5flourouracil pretreatment with $1 \mathrm{mg} \mathrm{kg}^{-1}$ was also decreasing the release of mebendazole from guar gum matrix tablets. The percent of drug released with 1,3 , or $6 \mathrm{mg} \mathrm{kg}^{-1} 5-\mathrm{FU}$ oral treatment was less than that obtained without rat caecal contents indicating that the GI flora was inactivated at the dose levels of 6,3 or $1 \mathrm{mg} \mathrm{kg}^{-1} 5$-fluorouraicl oral treatment. Due to the cytotoxic activity of 5-fluorouracil [21] against the anaerobic bacteria, the rat's GI flora might have been inactivated to a varying degree depending on the dose of 5fluorouracil administered. However, there was no significant difference $(\mathrm{P}>0.05)$ in the percent of mebendazole released after treatment with $0.3 \mathrm{mg} \mathrm{kg}^{-1}$ of 5 -fluorouracil when compared to control study in simulated colonic fluids-I (Fig. 3). Thus, the release of mebendazole from guar gum formulations was found to increase with a decrease in the dose of 5fluorouracil administered.

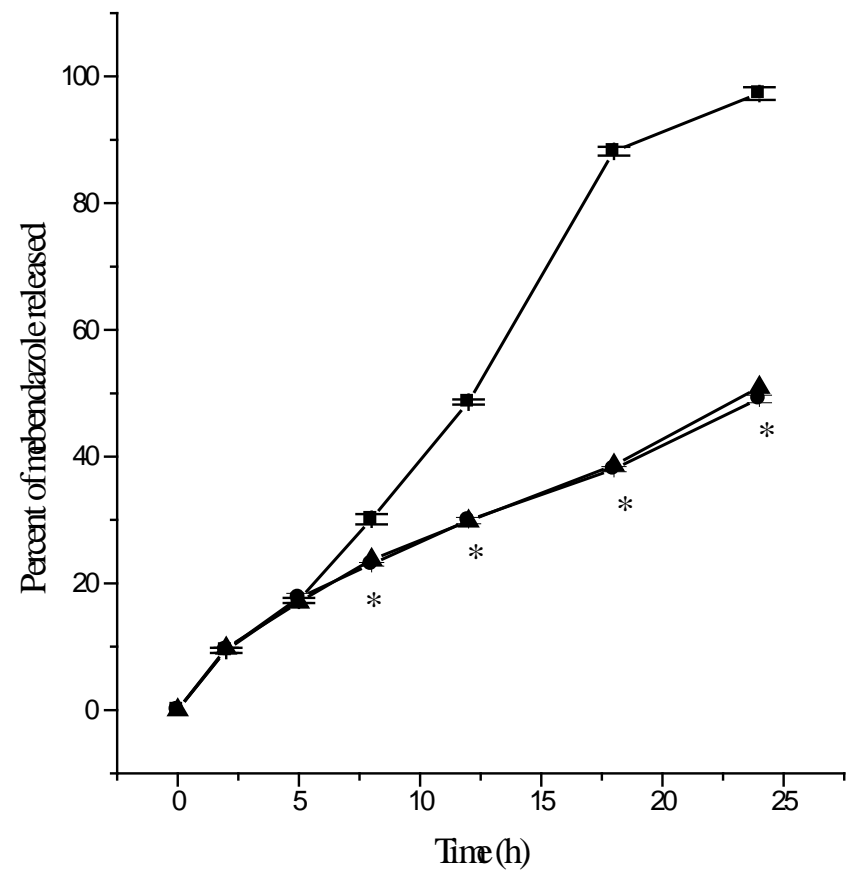

Fig. (2). Effect of $3 \mathrm{mg} \mathrm{kg}^{-1}(\bullet)$ and $6 \mathrm{mg} \mathrm{kg}^{-1}$ (A) oral 5fluorouracil pretreatment on the mean $( \pm$ S.D. $)$ percent of mebendazole released from guar gum matrix tablets $(n=3)$ of mebendazole in $0.1 \mathrm{M} \mathrm{HCl}(2 \mathrm{~h}), \mathrm{pH} 7.4$ phosphate buffer $(3 \mathrm{~h})$ and simulated colonic fluids-I [ ] (control) or simulated colonic fluids-II $(19 \mathrm{~h})$. *: Significant at $\mathrm{P}<0.001$.

Guar gum-based formulations of 5-fluorouracil contained $50 \mathrm{mg}$ of the drug in the core that was compression-coated with guar gum granules [24]. The dose contained in this formulation conforms to a dose of $0.83 \mathrm{mg} \mathrm{kg}^{-1}$ body weight (assuming average body weight of humans $60 \mathrm{~kg}$ ) which would be almost delivered only in the colon. In the present study, treatment with 5-fluorouracil for 5 days at a dose of $0.3 \mathrm{mg} \mathrm{kg}^{-1}$ did not significantly affect the release of the drug from the guar gum matrix tablets of mebendazole (Fig. 3) wherein a dose of 1,3 or $6 \mathrm{mg} \mathrm{kg}^{-1}$ greatly affected the release of the drug from the formulation (Fig. 2). Thus, the present study shows that the release of the drug from guar gum-based formulations of 5-fluorouracil that conforms to a dose of $0.83 \mathrm{mg} \mathrm{kg}^{-1}$ body weight (assuming average body weight of humans $60 \mathrm{~kg}$ ), as described previously, would not be affected on multiple administration of these formulations to the patients suffering from colorectal cancer. As a result, the 5-fluorouracil formulations are likely to release the expected quantity of the drug contained in the guar gum-based colonic drug delivery systems on chronic administration of these formulations in the treatment of colorectal cancer.

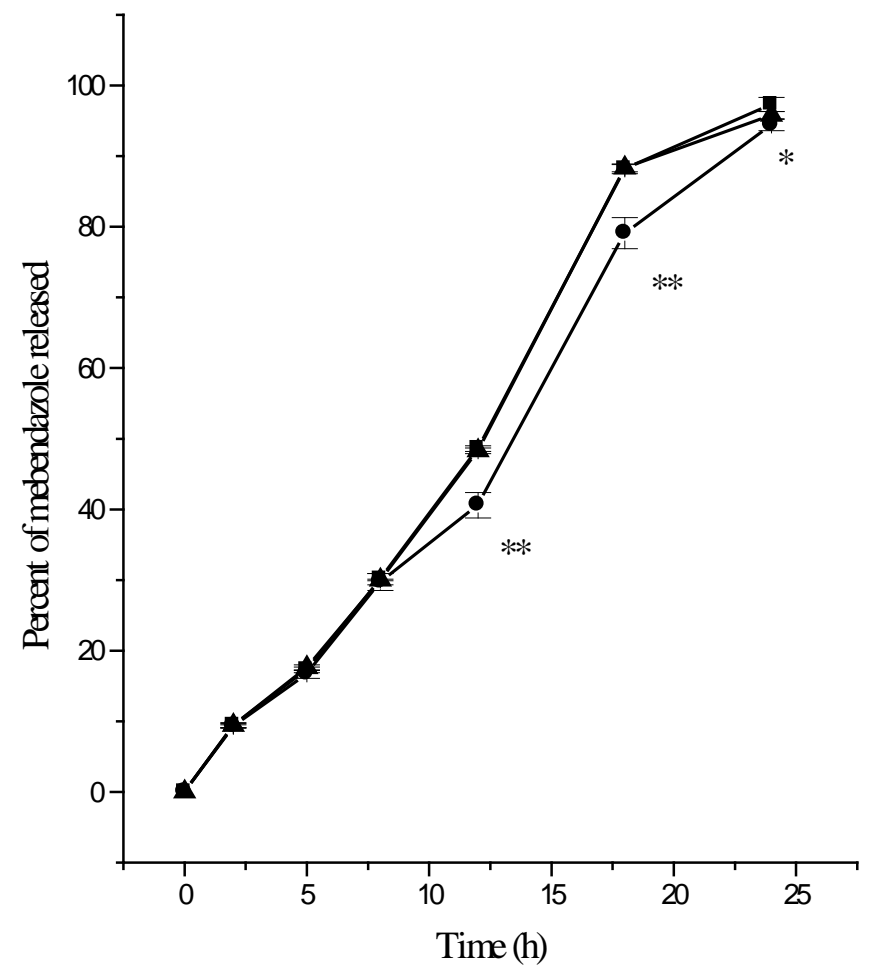

Fig. (3). Effect of $0.3 \mathrm{mg} \mathrm{kg}^{-1}(\boldsymbol{\Delta})$ and $1 \mathrm{mg} \mathrm{kg}^{-1}(\bullet)$ oral 5fluorouracil pretreatment on the mean $( \pm$ S.D. $)$ percent of mebendazole released from guar gum matrix tablets $(n=3)$ of mebendazole in $0.1 \mathrm{M} \mathrm{HCl}(2 \mathrm{~h}), \mathrm{pH} 7.4$ phosphate buffer $(3 \mathrm{~h})$ and simulated colonic fluids-I [ $\mathbf{a}$ (control) or simulated colonic fluids-II $(19 \mathrm{~h})$. $*$ : Significant at $\mathrm{P}<0.05 ; * *$ : Significant at $\mathrm{P}<0.01$.

\section{CONCLUSIONS}

The results of in vitro drug release studies with the chosen guar gum model formulation showed that oral pretreatment with $0.3 \mathrm{mg} \mathrm{kg}^{-1}$ of 5-fluorouracil did not affect their colon-targeting ability. Thus, it was concluded that the cytotoxic 5-fluorouracil, expected to be released in the physiological environment of colon from the first dose of guar gum-based formulations (dose $50 \mathrm{mg}$ ), is unlikely to affect the colon-targeting ability of guar gum formulations of 5 -flourouracil.

\section{ACKNOWLEDGEMENTS}

The authors greatly acknowledge M/s CIPLA Ltd., Bangalore, India, M/s East India Pharmaceutical Works Limited, Kolkata, India and M/s Dabur Research Foundation, New 
Delhi, India for the gift samples of mebendazole, tinidazole and guar gum respectively.

\section{REFERENCES}

[1] Moore, W.E.C.; Holdeman, L.V. Cancer Res., 1975, 35, 3418.

[2] Rubunstein, A. Biopharm. Drug Dispos., 1990, 11, 465.

[3] Cummings, J.H.; Englyst, H.N. Am. J. Clin. Nutr., 1987, 45, 1243.

[4] Scheline, R.R. Pharmacol. Rev., 1973, 25, 451.

[5] Potts, J.E.; Clendinnings, R.A.; Ackard, W.B.; Wiegisch, W.D. In Polymer Science and Technology, Guillet, J. Ed.; Plenum Press: New York, 1973, vol. 3, pp. 61-79.

[6] Huang, S.I.; Bansleben, D.A.; Knox, J.R. J. Appl. Polym. Sci., 1979, 23, 429 .

[7] Swift, G. Proc. ACS Div. Polym. Mater. Sci. Eng., 1992, 66, 403.

[8] Ratner, B.D.; Gladhill, K.W.; Horbett, T.A. J. Biomed. Mater. Res., 1988, 22, 509.

[9] Hergenrother, R.W.; Wabewr, H.D.; Cooper, S.L. J. Appl. Biomat., 1992, 3, 17.

[10] Park, K.; Shalaby, S.W.W.; Park, H. Biodegradable Hydrogels for Drug Delivery, Technomic Publishing Company: New York, 1993.

[11] Wakerly, Z.; Fell, J.T.; Attwood, D.; Parkins, D.A. Int. J. Pharm., 1996, 129, 73.

[12] Milojevic, S.; Newton, J.M.; Cumminings, J.H. Gibson, G.R.; Botham, R.L.; Ring, S.G.; Allwood, M.; Stockham, M. STP Pharma. Sci., 1995, 5, 47.

[13] Rubinstein, A.; Nakar, D.; Sintov, A. Int. J. Pharm., 1992, 84, 141.

[14] Rama Prasad, Y.V.; Krishnaiah, Y.S.R.; Satyanarayana, S. J. Control. Release, 1998, 53, 281.
[15] Krishnaiah, Y.S.R.; Satyanarayana, S.; Rama Prasad, Y.V.; Narasimha Rao, S. J. Control. Release, 1998, 55, 245.

[16] Krishnaiah, Y.S.R.; Satyanarayana, S.; Rama Prasad, Y.V.; Narasimha Rao, S. Int. J. Pharm., 1998, 171, 137.

[17] Goldstein, A.M.; Alter, E.N.; Seaman, J.K. In Industrial Gums, Polysaccharides and Their Derivatives, Whistler, R.L. Ed.; Academic Press: New York, 1993; pp. 303-321.

[18] Krishanaiah, Y.S.R.; Veer Raju, P.; Dinesh Kumar, B.; Bhaskar, P.; Satyanarayana, V. J. Control. Release, 2001, 77, 87.

[19] Krishnaiah, Y.S.R.; Bhaskar Reddy, P.R.; Satyanarayana, V.; Karthikeyan, R.S. Int. J. Pharm., 2002, 236, 43.

[20] Krishnaiah, Y.S.R.; Satyanarayana, V.; Kumar, B.D.; Karthikeyan, R.S. J. Drug Target., 2002, 10, 247.

[21] Calabresi, P.; Chabner, B.A., In Goodman \& Gilman's The Pharmacological Basis of Therapeutics; Hardman, J.G.; Limbird, L.E.; Perry, B.M.; Raymond, W.R. Eds.; McGraw-Hill: New Delhi, 1996; $9^{\text {th }}$ ed., pp. $1225-1232$.

[22] Hahn, R.G.; Moertel, C.G.; Schutt, A.J. Cancer, 1975, 35, 1031.

[23] Diasio, R.B.; Harris, B.E. Clin. Pharmacokinet., 1989, 16, 215.

[24] Krishnaiah, Y.S.R.; Satyanarayana, V.; Kumar, B.D.; Karthikeyan, R.S. Eur. J. Pharm. Sci., 2002, 16, 185.

[25] British Pharmacopoeia 2000, The Stationery Press: London, 2000.

[26] Bayliss, C.E.; Houston, A.P. Appl. Environ. Microbiol., 1986, 48, 626.

[27] Macfarlane, G.T.; Hay, S.; Macfarlane, S.; Gibson, G.R. J. Appl. Bacteriol., 1990, 68, 179.

[28] Tomolin, J.; Taylor, J.S.; Read, N.W. Nutr. Rep. Int., 1989, 39, 121. 